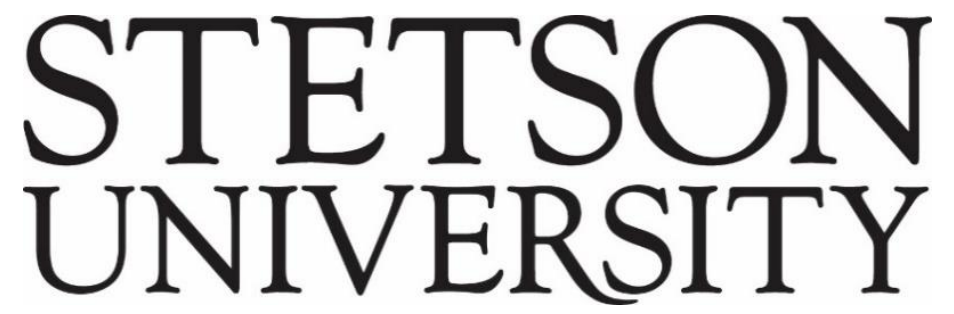

Voices of Reform: Educational Research to Inform and Reform

Volume 3 - Issue 2 - Article 2

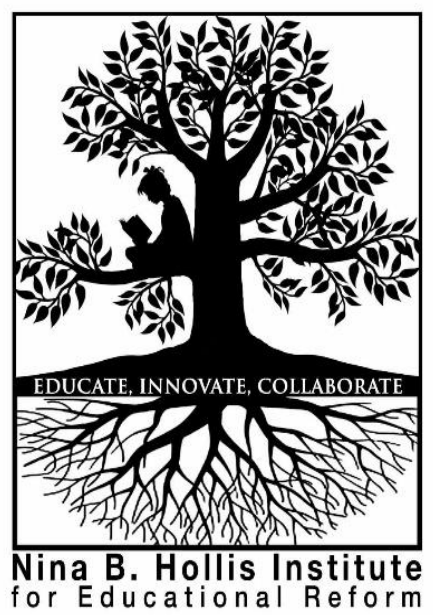

December 2020

\title{
Preparing Scholar-Practitioners for Systemic and Systematic Inquiry: Methodology Published and Practiced
}

Susan Curtin

University of South Dakota

David DeJong

University of South Dakota

Derrick Robinson

University of Memphis

Karen Card

University of South Dakota

Ayana Campoli

Learning Policy Institute

Follow this and additional works at: http://www.voicesofreform.com

Recommended Citation

Curtin, S., DeJong, D., Robinson, D., Card, K., Campoli, A. (2020). Preparing scholar-practitioners for systemic and systematic

inquiry: Methodology published and practiced. Voices of Reform, 3(2), 40-70. Retrieved from

https://www.voicesofreform.com/article/18593-preparing-scholar-practitioners-for-systemic-and-systematic-inquiry-

methodology-published-and-practiced doi: 10.32623/3.10004

http://dx.doi.org/10.32623/3.10004

Revisions

Submission date: May $7^{\text {th }}, 2020$

$1^{\text {st }}$ Revision: July $8^{\text {th }}, 2020$

Acceptance: July $12^{\text {th }}, 2020$

Publication date: December $29^{\text {th }}, 2020$ 


\title{
Preparing Scholar-Practitioners for Systemic and Systematic Inquiry: Methodology Published and Practiced
}

\author{
Susan Curtin ${ }^{1}$ \\ David DeJong ${ }^{2}$ \\ Derrick Robinson ${ }^{3}$ \\ Karen Card $^{4}$ \\ Ayana Campoli ${ }^{5}$ \\ ${ }^{1}$ Division of Educational Leadership and Administration \\ University of South Dakota, United States \\ susan.curtin@usd.edu \\ ${ }^{2}$ Division of Educational Leadership and Administration \\ University of South Dakota, United States \\ david.dejong@usd.edu \\ ${ }^{3}$ Department of Leadership \\ University of Memphis, United States \\ drbnsn28@memphis.edu \\ ${ }^{4}$ Division of Educational Leadership and Administration \\ University of South Dakota, United States \\ karen.card@usd.edu \\ ${ }^{5}$ Educator Quality Team \\ Learning Policy Institute, Palo Alto, California, United States \\ acampoli@learningpolicyinstitute.org
}

\begin{abstract}
This study explores the methodology presented in four leading educational leadership journals for a period of three years to investigate the predominant methodologies reported in journals most read by faculty members in educational administration or leadership programs. This content analysis study uses frequency and percentages to gather data on the published methodologies of four educational leadership journals. We used an established coding protocol, and our coding was not interpretive. The analysis revealed that qualitative methods were published more frequently
\end{abstract}


than quantitative methods in the leading educational leadership journals with an emphasis on studies using a descriptive qualitative design, a descriptive quantitative design, correlational research, and case studies. This study replicated a study conducted by Wells, Kolek, Williams, and Saunders (2015) which was a content analysis of three major higher education journals to examine the methodologic characteristics of published research from 1996-2000 and 2006-2010 respectively. The authors discuss the relevance of the study for EdD programs in Educational Administration/Leadership. The analysis may inform decisions about how to best develop scholarpractitioners' capacity to use systemic and systematic inquiry to solve complex problems of practice.

\section{Keywords}

research methods, educational leadership, content analysis, review of research, empirical research

\section{Introduction}

Educational leadership journals can both "create and mirror the fields" (Silverman, 1987, p. 40). Journals aim to publish rigorous and relevant research to extend knowledge, to share best practices and to promote critical feedback from peers. This creates conversations in the scholarly community and ultimately in classrooms. In this way, the leading journals in the field can inform and guide what we teach to develop the capacity for systemic and systematic inquiry and its application to solving complex problems of practice. Alternatively, articles published in leading educational journals may reflect the methodologies that are privileged in educational leadership programs. Do the methodologies published in the leading educational leadership journals reflect and advance the application of current research practices in the field, or does published research guide what is taught in educational leadership programs? The conversation about which methodologies should be taught in an educational leadership program to prepare scholar-practitioners for systemic and systematic inquiry in practice prompted this study.

The medical community uses evidence-based practices published in scientific journals to swiftly communicate across institutions, countries, and fields how current research builds upon previous research and extends it to the next level. Often influenced by federal and state mandates, school districts are often under pressure to use evidence-based research, but published research is not always context specific nor reviewed by those who are implementing the policies, procedures, and instructional practices. Thus, practitioners may turn to anecdotal evidence to solve complex problems rather than follow published research strands or using methodologies learned in educational leadership programs. Scholars, on the other hand, may continue to conduct research using methodologies that are likely to be published, but that do not necessarily build on previous research broadening the scope to make it more context specific. Among graduate programs the question of how research influences who learns what and how is worthy of discussion.

Educational leadership programs endeavor to ensure that graduates are equipped with the knowledge, skills, and dispositions needed for contemporary school leadership by providing content and experiences that reflect current evidence-based practices appearing in the leading research journals. Educational leadership programs aim to prepare graduates to critically read 
published research with intermediate and advanced techniques, apply evidence-based research to practice, and to share their own research in top-tier journals as scholar-practitioners. Preparation programs strive to provide a breadth of methodologies to consider when critically examining problems of practice. They also expect a thoughtful reflection upon which methodology best answers the research question to inform practice. We know that professors in educational leadership programs are preparing emergent scholar-practitioners with the knowledge and skills to read, understand, and utilize current research. The question that guided our interest in this research project and continues to inform our decisions about who, what, why, and in what ways we teach future educational leaders is how well we prepare scholar-practitioners to apply the published research to their own context. Additionally, how have methodologies appearing in major journals evolved as our research questions and practices have evolved?

\section{Previous Research}

Previous studies by Hallinger (2013), Hutchinson and Lovell (2004), and Wells, Kolek, Williams, and Saunders (2015) conducted content analyses of three major higher education journals to examine the methodologic characteristics of published research from 1996-2000 and 2006-2010 respectively. These studies based their work on that of Silverman (1987) who for higher education journals explored the question "How we know what we know--what topical areas have been presented in journals and through what article structures" (p. 40). He noted that a variety of topics and inquiry approaches should be published continuously to address what those in the discipline wish to know. While Silverman focused on journals in higher education, the same could be said for educational leadership. How does research published in educational journals respond to or shape what leaders and/or those preparing leaders want to know?

At approximately the same time period Goodwin and Goodwin (1985) conducted a study of statistical techniques in the American Educational Research Journal and found a predominance of basic, intermediate, and advanced statistics in that order. They discuss the implications for teaching research statistics in graduate school and also note that the trend remained steady over a four-year span (1979-1983). Additionally, developmental research in the social sciences has evolved to include approaches such as latent variable modeling and planned missing data, to improve research by avoiding biased results and conclusions (Little, Gorrall, Panko, \& Curtis, 2017). While also applying biopsychosocial models of human development to encourage a more comprehensive examination of school and system interventions and the implications for each student (Kranzler, Floyd, Bray, \& Demaray, 2020) as opposed to applying the intervention to all students.

We pondered the implications for graduate research statistics coursework in educational leadership programs. As a result we chose to replicate the methodology of Wells et al. (2015) who define basic statistical analysis as ANOVA, correlation, chi-squared, $\mathrm{T}$ test, and descriptives; intermediate statistical analysis as ANCOVA, multiple regression, path modeling, planned orthogonal comparisons and post hoc comparisons; and advanced statistics such as cluster analysis, factor analysis, logistic regression, MANOVA, structural equation modeling, and hierarchical linear modeling. This study replicated a study by Hutchinson and Lovell (2004), a content analysis of methodological characteristics of three major higher education journals from 2006-2010. More 
recently Jackson (2019) conducted an exploratory study aimed at research methodology in three educational leadership ICPEL journals during the years 2013-2017. Wells et al. note that the journals use increasingly more advanced statistics. Again, we wondered would the same hold true for four leading educational leadership journals and how does that inform our preparation of future leaders?

Goodwin and Goodwin (1985) suggest that graduate students in higher education would be prepared to read the educational research literature with an understanding of basic and intermediate level statistics. Richardson and McLeod (2009) explored a potential mismatch in what is taught, what is read, and what is written and suggested that though instructors in educational leadership programs continue to read primary research articles, practitioners more often read executive summaries or secondary research. Silverman also alluded to this mismatch between what is written and the interests or needs of the reader. Hutchinson and Lovell (2004) further suggest that in order for published material to be appreciated and fully understood by graduate students and those in the field, modifications in graduate-level research training may need to occur. Do we prepare our educational leaders not only to read and to understand current research but also to produce research of sufficient quality to be published by leading educational leadership journals? While several of these studies explored methodological approaches in higher education journals, a study is lacking that focuses upon content analysis of methodological characteristics across journals, which led us to replicate the Wells et al. (2015) study for four key educational leadership journals.

\section{Methodology}

This study employs a quantitative approach informed by a descriptive analysis of 255 peerreviewed scholarly articles published in four leading educational leadership journals from 20142016. To construct our study, we reviewed prior research on educational leadership journals and, through a peer debriefing process, selected four journals for the study. The four journals are: a) the Journal of School Leadership, b) the Journal of Educational Administration, c) Educational Administration Quarterly, and d) the National Association of Secondary School Principals Journal. This adds to the work of Jackson (2019) who conducted an exploratory study of research methodologies for three journals: a) the Education Leadership Review; b) the International Journal of Educational Leadership Preparation, and c) The Journal of Research on Leadership Education. However, there are differences in the two studies. While we examined different journals, our study also contrasts this more recent study in the quantitative approach used.

\section{Journal Selection}

The selection of journals for this study involved the development of inclusionary criteria. Influenced by the collective readings of Richardson and McLeod (2009), Hutchinson and Lovell (2004), Silverman (1987), and Wells, Kolek, Williams, and Saunders (2015), we crafted a selection process based on three criteria: (a) reputation in the discipline, (b) use of blind, peer-reviewed process, and (c) evidence of ranking or indexing by independent evaluators.

Criterion Explanation. Reputation for research and practice aligns with the purpose of this study. We seek to explore and analyze published research in top-tier journals in educational leadership. Focusing on identified educational leadership journals in research and practice, we also wanted to 
ensure that they follow a blind, peer-reviewed process to ensure the integrity of their work. This process was necessary as approval from scholars in the field is necessary for the academic community. Finally, we wanted to determine the ranking or indexing of the identified journals. In this process, we discovered that not every journal is ranked or evaluated by a sole, independent evaluator. For example, while Scimago (n.d.) offers a wide range of academic journal rankings, they have not evaluated the Journal of School Leadership. However, Google Scholar (n.d.) produces h-5 index rankings but have not evaluated the National Association of Secondary School Principals journal, NASSP.

As a collective group, we decided to use the h5-index, which measures a 5-year citation evaluation of a published journal, and the h-index, which provides a general measure of the number of articles that have received citations over a general period (Google Scholar, n.d.; Scimago, n.d.). Citations, and citation indexes, are an important measure for research scholars, as they are an indication of the times an author's work has influenced scholars and peers in the field (American Psychological Association, 2020). We also included in our evaluation and selection the notion of acceptance rates. Acceptance rates are important as they speak to the reputation of a journal and the competitiveness to publish in a journal.

Reputation in the Discipline. Guided by the research question, What methodologies are published in leading educational leadership journals from 2014-2016, the researchers adapted the form and methodology used by Wells et al. (2015) in their content analysis of higher education journals and applied it to a content analysis of methodologies found in four leading educational leadership journals. This study investigated the methodological characteristics of published research in the field of educational leadership preparation, particularly those journals suggested by the research of Richardson and McLeod (2009) as among the top ten journals where educational leaders should publish to get noticed by the top journals in the discipline. The authors cite Educational Administration Quarterly (EAQ) and the Journal of School Leadership (JSL) as the most cited journals by scholars publishing in the field of educational leadership. Our study investigated methodologies in these two journals and included Journal of Educational Administration (JEA), the fifth most cited journal in JSL and the seventh most cited journal in EAQ and the National Association of Secondary School Principals Bulletin, which was listed as the sixth most cited educational leadership journal in JSL. We chose not to include Phi Delta Kappan and Educational Leadership as the research published in these journals did not match the criteria though they were listed in the ten top journals by Richardson and McLeod (2009). Mayo, Zirkel, and Finger (2006) also found that professors of education leadership ranked EAQ and American Educational Research Journal as the top ranked educational leadership periodicals and also the most read after Educational Leadership and Phi Delta Kappan which further supported our selection of journals to review.

Review and Ranking. All of the reviewed journals require a blind, peer-reviewed process and focus on topics within the field of educational leadership. The Educational Administration Quarterly $(E A Q)$ publishes manuscripts on various topics including educational leadership, organizations, leadership development, and policy as they relate to elementary and secondary levels of education. $E A Q$ 's editors and editorial team have established goals to publish research that promotes dialogue 
among scholars and practitioners. EAQ has a h-index of 75, an h5-index of 36, and an acceptance rate of 6 - 10\%. The Journal of School Leadership (JSL) is focused on schools and leadership in education and invites manuscripts from all theoretical and methodological approaches. JSL also welcomes manuscripts that include themes of teacher, student, parent, and community leadership. JSL has a h5-index of 17 and an acceptance rate of 6 - 10\%. The Journal of Educational Administration (JEA) aims to publish research in educational leadership in various contexts such as political, economic, and socio-culture. The editors of JEA focus on broad topics within K-12 school leadership and invite studies grounded in qualitative, quantitative, and mixed methods methodologies. JEA has a h-index of 55, a h5-index of 30, and an acceptance rate of $21-30 \%$. Finally, the National Association of Secondary School Principals (NASSP) Bulletin aims to inform practice, support data-driven decisions, advance the vision and performance of middle level and high school principals. The editors of the NASSP Bulletin welcome manuscripts that promote student learning, focus on strategic planning, and provide perspectives on reforms in education. The NASSP Bulletin has a h-index of 23 and an acceptance rate of $21-30 \%$.

The previous research upon which this study is based (Goodwin \& Goodwin, 1985; Hutchinson \& Lovell, 2004; Silverman, 1987; Wells, Kolek, Williams, \& Saunders, 2015) each reviewed five years of issues for a limited number of journals. As the previous studies utilized no greater than three journals, we chose to broaden the number of journals in this study to four and chose a period of three years to offer the most current data. The study was conducted over a period of eighteen months during which three primary researchers reviewed all research articles published in the journals and coded each article using an adapted version of the Wells et al. methodology. Two additional researchers offered feedback on the form and process as well, which contributed to reliability. We were guided by the criteria cited by Hallinger (2013) as important for systematic reviews. Our methods were explicit and transparent and replicated previous studies with fidelity.

\section{Data Collection}

As a team of researchers, we established a common shared electronic folder to store the 255 peerreviewed journal articles published in our targeted journals. Moreover, aligning with Wells et al. (2015), we selected targeted variables and constructed a common form by which information from each article could be analyzed and aggregated. Variables were categorized into three areas: a) general variables, article name, research approach, and research design; b) qualitative variables, research design, data collection technique, analysis procedures; and c) quantitative variables, research design, data collection technique, analysis procedures. The general variables allowed us to speak on publications as a whole and to separate publications by qualitative, quantitative, mixed methods, and other approaches. The qualitative and quantitative variable categories allowed us to examine articles and publications based on more specific study designs, techniques, and levels of analysis.

Data Analysis. As with Wells et al. (2015), the data extracted from the common form was saved into an Excel spreadsheet, coded for each variable and publication, and then cleaned and uploaded into SPSS. The analysis in SPSS included performing descriptive statistical analysis to determine the frequencies of variables within the study. Prior to that analysis, the research team performed 
routine peer debriefing on the data extracted within the Excel spreadsheet to affirm consistency in the coding process.

\section{Coding Procedures}

All authors analyzed four articles as a group until we had established inter-rater consistency. Each of the authors read the same article, completed the data coding form individually, and shared their results in a group discussion. We continued this process until we were confident that we were at least $95 \%$ consistent. When we decided that we had achieved adequate inter-rater consistency, we divided the journals among researchers with two researchers assigned to each journal so that one author's perspective did not dominate. During weekly research meetings, we added or deleted items to the adapted form to further clarify terminology or provide information that we felt important, but were not included in the original form. Articles in question were presented for group analysis or for verification prior to submitting the form. Researchers also consulted one another when a question arose. These two precautions increased the consistency of responses. The adapted form is included in Appendix A.

The coding form was identical for all researchers. The form began with the coder initials, the journal name, title of the article, and keywords. The next page required the researcher to identify the design used, the broad design type (quantitative, qualitative, or mixed), and the data collection method. Following this, the researcher indicated the type of statistical analysis used (basic, intermediate, advanced) and responded to questions designed to reveal the quality of the approach. We added a section for comments, questions, or notations as a means of communication with all researchers.

Our coding was not interpretive. For example, if the researchers reported that they addressed missing data, we indicated yes. If it was not mentioned, we indicated that it was not specified. Though in some cases it may have been implicitly understood, we recorded what was reported, such as in the case of interviews being transcribed or recorded or whether triangulation was discussed. We did this to ensure consistency and to report what was written. This increased our confidence that raters were coding consistently. When a research method was used that could not be applied to a given category, we indicated this in the section titled "other."

We chose to record empirical articles only and did not report expository, historical, opinion essays, or book reviews. While Wells et al. (2015) chose to include expository, opinion pieces, and historical reviews, we chose a focus of methodology for this study.

\section{Data Analysis}

The researchers determined frequencies and percentages of broad research designs, data collection sources/methods, statistical analyses, quality of research (bias, reliability, validity, recording and transcribing, coding procedures) across all journals and among each journal. The total number of articles included 271 peer reviewed research articles from the four journals. The number of nonresearch articles, such as book reviews/essays/historical reviews, was omitted thus leaving a sample of 255 articles. The purpose of the study was to explore published research in top-tier educational leadership journals in general, but differences among the journals were of interest. 


\section{Overall Results}

In examining the distribution of research articles published in the selected leading educational leadership journals from 2014 to 2016, we conducted coding strategies to analyze all published articles within this time frame. As qualitative and quantitative research approaches comprised of $44.3 \%$ and $35.3 \%$, respectively, of all research publications in the selected study period, we provide an analysis of each approach as a separate entity.

\section{Publications from 2014-2016}

From 2014 to 2016, there were 255 journal articles published by these four educational leadership journals selected for this study. Of those 255 journal articles, the Journal of School Leadership constituted 79 (31\%) of articles used in this period of study, followed closely by the Journal of Educational Administration with 75 articles at 29.4\%, as shown in Table 1. Educational Administration Quarterly had 61 articles or $23.9 \%$ and National Association of Secondary School Principals, had 40 articles at $15.7 \%$ of the articles published in this study period. 
Curtin, DeJong, Robinson, Card, and Campoli: Preparing scholar-practitioners for systemic and systematic inquiry: Methodology published and practiced

Table 1: Journal Frequency Distribution

\begin{tabular}{llll} 
Journal & Frequency & Percent & Valid Percent \\
\hline EAQ & 61 & 23.9 & 23.9 \\
JEA & 75 & 29.4 & 29.4 \\
JSL & 79 & 31.0 & 31.0 \\
NASSP & 40 & 15.7 & 15.7 \\
\hline
\end{tabular}

Note: This data represents the frequency distribution for all journals used in this study. 
Research Approach. Of the 255 journals reviewed in this study, the most dominant approach was qualitative at $44.37 \%$ followed by quantitative research approaches which were $35.3 \%$. The mixed methods approach accounted for only $16.1 \%$ of the research approaches in this time period. Only $5.5 \%$ of the articles fell into the "other" category.

Research Designs. As shown in Table 2, descriptive qualitative research design accounts for $31.8 \%$ of all research designs used. Correlational research designs followed closely at $20.8 \%$ of the research designs. Case study and descriptive quantitative research designs accounted for $16.9 \%$ and $15.7 \%$ of the research designs. Four designs accounted for $94 \%$ of all research studies. 
Table 2: Frequency by Research Design

\begin{tabular}{|c|c|c|c|}
\hline & Frequency & Percent & Valid Percent \\
\hline Descriptive Qualitative & 81 & 31.8 & 31.8 \\
\hline Correlational & 53 & 20.8 & 20.8 \\
\hline Descriptive Quantitative & 40 & 15.7 & 15.7 \\
\hline Literature, theoretical, conceptual & 10 & 3.9 & 3.9 \\
\hline Quasi experimental & 7 & 2.7 & 2.7 \\
\hline Other & 6 & 2.4 & 2.4 \\
\hline Causal Comparative & 4 & 1.6 & 1.6 \\
\hline Experimental & 4 & 1.6 & 1.6 \\
\hline Longitudinal & 3 & 1.2 & 1.2 \\
\hline Ethnography & 3 & 1.2 & 1.2 \\
\hline Narrative & 1 & .4 & .4 \\
\hline Total & 255 & 100.0 & 100.0 \\
\hline
\end{tabular}

Note: This data represents the frequency distribution for all journals used in this study. 


\section{Qualitative Approaches}

Of the 255 published articles in the educational leadership journals selected in this study period, 113 articles employed a qualitative approach. Most of these (42, or 37.2\%) were published in the Journal of School Leadership, whereas the Educational Administration Quarterly and the Journal of Educational Administration comprised of $25.7 \%$ and $22.1 \%(\mathrm{n}=25)$ of the qualitative journal articles, respectively. An additional $17(15 \%)$ articles were published in NASSP. Looking at the data another way, over half $(53.2 \%)$ of the articles published in $J S L$ were qualitative designs whereas only a third (33.3\%) of those in $J E A$ were qualitative. Qualitative was still the predominant methodology used in EAQ (47.5\%) and NASSP (42.5\%).

Research Designs. In examining the qualitative research designs of articles published in the selected journals from 2014 to 2016, descriptive qualitative and case study designs accounted for $54 \%$ and $35.4 \%$ of the research designs observed in the study of selected journals as shown in Table 3. This observation suggests that the editorial boards deem these methods as appropriate for their readership. 
Curtin, DeJong, Robinson, Card, and Campoli: Preparing scholar-practitioners for systemic and systematic inquiry: Methodology published and practiced

Table 3: Frequent Distribution by Qualitative Research Design

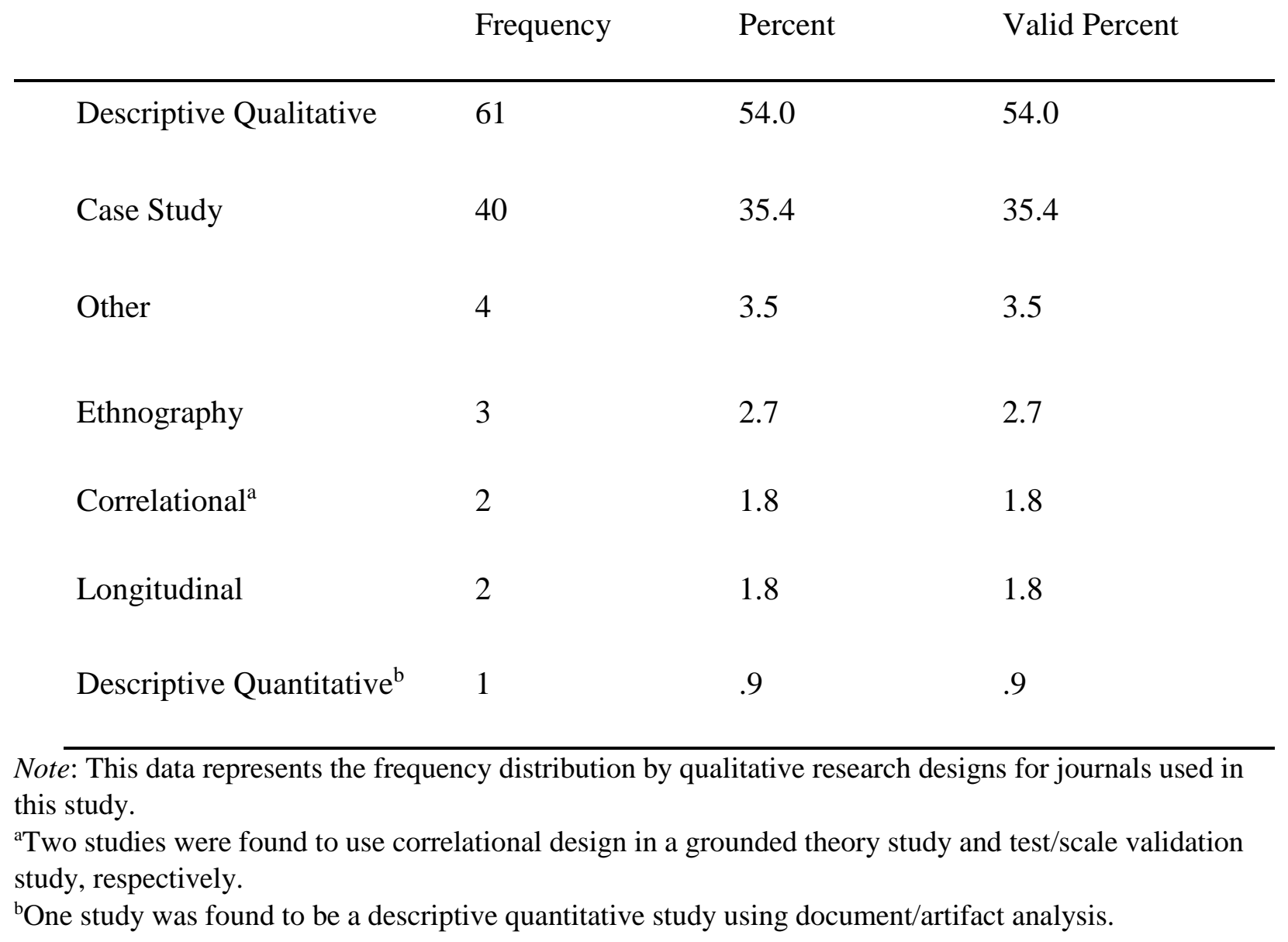


Data Collection Techniques. Our examination of the qualitative articles published in our targeted educational leadership journals from 2014-2016 permitted us to see which data collection tools were utilized by the researchers. In examining the data collection techniques, it was discovered that, of the 113 qualitative articles, 48 , or $42.5 \%$, were comprised of interviews as a primary data collection tool. The next most frequently used primary data collection tool, as shown in Table 4, was the use of observation, which accounted for $32.7 \%$, in 37 of the 113 qualitative articles. Qualitative surveys and document/artifact studies comprised of 13.3 and $8.8 \%$ of the primary qualitative data collection tools observed in the selected journals from 2014 to 2016. 
Curtin, DeJong, Robinson, Card, and Campoli: Preparing scholar-practitioners for systemic and systematic inquiry: Methodology published and practiced

Table 4: Frequency Distribution by Qualitative Data Collection Techniques

\begin{tabular}{lccc} 
& Frequency & Percent & Valid Percent \\
\hline Survey & 15 & 13.3 & 13.3 \\
Observation & 37 & 32.7 & 32.7 \\
Interview & 48 & 42.5 & 42.5 \\
Document/Artifacts & 10 & 8.8 & 8.8 \\
Other & 3 & 2.7 & 2.7 \\
\hline
\end{tabular}

Note: This data represents the frequency distribution by qualitative data collection for journals used in this study. 
Further Qualitative Research Observations. Our analysis of published qualitative articles in the targeted educational leadership journals from 2014-2016 also included findings addressing researcher bias statements, coding processes explained, and interview and focus group analysis procedures. Our analysis found that 90 of the 113 qualitative journal articles, or $79.6 \%$, did not discuss researcher bias within the article. However, we found that 102 of the 113 qualitative journal articles, or $90.3 \%$, provided an explanation of the coding process that was used to aid analysis in their studies. Further, our analysis finds that of the 113 qualitative journal articles examined, 62 (54.9\%), and $72(63.7 \%)$, of the journal articles explicitly mentioned the use of recorded and/or transcribing interviews and focus groups, respectively.

\section{Quantitative Approaches}

Of the 255 published articles in the educational leadership journals selected in this study period, 87 articles employed a quantitative approach. In examining journals by quantitative approaches, we find that the Journal of Educational Administration accounted for $35.6 \%$ of all quantitative research approaches from 2014 to 2016, as shown in Table 5. The Journal of School Leadership and Educational Administration Quarterly accounted for $26.4 \%$ and $21.8 \%$ of quantitative journal articles, respectively. The National Association of Secondary School Principals accounted for the remaining $16.1 \%$ of journal articles using a quantitative approach. This observation may suggest that the Journal of Educational Administration may provide a higher likelihood for the publication of quantitative journal articles. Looking more into this data, Journal of Educational Administration is the only journal in which the percent of quantitative statistics $(41.3 \%)$ exceeds that of qualitative (33.3\%) whereas NASSP tends to publish a greater proportion of qualitative $(53.2 \%)$ compared to quantitative $(24.1 \%)$ although both types of design are adequately represented in all journals. 
Curtin, DeJong, Robinson, Card, and Campoli: Preparing scholar-practitioners for systemic and systematic inquiry: Methodology published and practiced

Table 5: Journal Frequency Distribution

\begin{tabular}{lccc} 
Journal & Frequency & Percent & Valid Percent \\
\hline EAQ & 19 & 21.8 & 21.8 \\
JEA & 31 & 35.6 & 35.6 \\
JSL & 23 & 26.4 & 26.4 \\
NASSP & 14 & 16.1 & 16.1 \\
Total & 87 & 100.0 & 100.0
\end{tabular}

Note: This data represents the frequency distribution for quantitative journals used in this study. 
Research Designs. In examining the quantitative research designs of articles published in the selected journals from 2014 to 2016, 48.3\% employed correlational research design, as shown in Table 6. Descriptive quantitative research designs accounted for $36.8 \%$ of the quantitative journal articles observed in the selected journals from 2014 to 2016. It is important to note the causal comparative, quasi-experimental, and experimental research designs combined accounted for only $10.5 \%$ of quantitative research designs in the journals observed in this study. This may suggest, for this selected period of study, quantitative research that explores relationships or descriptive studies that explain regression or variance are preferred research designs. 
Curtin, DeJong, Robinson, Card, and Campoli: Preparing scholar-practitioners for systemic and systematic inquiry: Methodology published and practiced

Table 6: Frequency by Quantitative Design

Frequency Percent $\quad$ Valid Percent

$\begin{array}{lccc}\text { Correlational } & 42 & 48.3 & 48.3 \\ \text { Descriptive Quantitative } & 32 & 36.8 & 36.8 \\ \text { Quasi experimental } & 6 & 6.9 & 6.9 \\ \text { Experimental } & 2 & 2.3 & 2.3 \\ \text { Causal Comparative } & 2 & 2.3 & 2.3 \\ \text { Case Study } & 1 & 1.1 & 1.1 \\ \text { Descriptive Qualitative } & 1 & 1.1 & 1.1 \\ \text { Longitudinal } & 1 & 1.1 & 1.1 \\ \text { Total } & 87 & 100.0 & 100.0\end{array}$

Note: This data represents the frequency distribution for quantitative designs used in this study.

${ }^{a}$ The case study was a social network analysis that uses descriptive statistics.

${ }^{b}$ The descriptive qualitative study here is a study that used surveys as primary data collection tools, Delphi Survey. 
Data Collection Techniques. Our examination of the quantitative articles published in our targeted educational leadership journals from 2014-2016 permitted us to see which data collection tools were utilized by the researchers. In examining the data collection techniques, it was discovered that, of the 87 quantitative articles observed in this study, 75 (86.2\%), involve the use of quantitative surveys as a primary data collection technique, as shown in Table 7. There appears to be limited use of observational, national, document, or organizational data, $13.8 \%$ combined. 
Curtin, DeJong, Robinson, Card, and Campoli: Preparing scholar-practitioners for systemic and systematic inquiry: Methodology published and practiced

Table 7: Frequency by Quantitative Data Collection Techniques

\begin{tabular}{llll} 
& Frequency & Percent & Valid Percent \\
\hline Survey & 75 & 86.2 & 86.2 \\
& 2 & 2.3 & 2.3 \\
Observation & & & \\
& 2 & 2.3 & 2.3 \\
National data/ Literature research & 2 & & \\
& & & \\
& 7 & 8.0 & \\
Document/Artifacts & 1 & 1.1 & 1.1
\end{tabular}

Note: This data represents the frequency distribution for quantitative data collection techniques used in this study. 
Further Quantitative Research Observations. Our analysis of published quantitative articles in the targeted educational leadership journals from 2014-2016 also included findings addressing quantitative levels, statistical levels of primary research questions, and description and justification of missing data. An examination of the quantitative levels of study indicates a heavy influence on the use of advanced inferential statistics. In this observation, $60.9 \%$ of the quantitative journal articles published in the selected journals utilizing advanced levels of inferential statistics. Of the 87 quantitative journal articles published from the selected journals, 54 (62.1\%), of the primary research questions involved advanced statistical levels of questioning. Further, in examining description and justification of missing data, 55 (63.2\%), of published researchers in the selected time period of this study provided no mention of missing data. Another quantitative observation is that the most frequently (20 times or more) used keywords include: leadership, school, principal, teacher, educational, social, develop, education, organizational, instructional, leader, learn, professional, administration, student, reform, policy, and manage. These keywords may provide a framework of matching scholar-practitioners with dissertation advisors based on a scholarpractitioner's desired opportunity for change within their dissertation.

\section{Conclusions}

Our research revealed some surprises including that there were more primary surveys than secondary surveys and that the use of national databases was scant. While Hochbein \& Smeaton (2018) found more quantitative research than qualitative research in some different educational leadership journals, our research revealed more qualitative studies than we expected.

\section{Implications for Preparation of Scholar-Practitioners}

The results of this study suggest immediate and long-term implications for graduate programs in educational leadership. When research holds meaning and guides instructional decision-making, instructional leaders are able to use evidence-based research with confidence and contextual relevance. Educational research questions may be best answered using basic or intermediate techniques, however, it also may be that researchers and faculty members may be less familiar or comfortable with advanced techniques which has implications for researchers and their students. As Goodwin and Goodwin (1985) found in their review of the American Educational Research Journal (AERJ), knowing the published research in the field, informs "professors of graduate-level statistics, research methods, measurement, and related courses" (p. 5) in the areas of curriculum development and of textbook selection.

Our results revealed that professionals in the educational leadership field require a grounding in intermediate-level statistics and qualitative research methodologies to adequately comprehend published research. Goodwin and Goodwin (1985) suggest that an understanding of basic and intermediate statistics is sufficient to read research literature, while Hutchinson and Lovell (2004) believe that educational leadership programs need to ensure that doctoral graduates are prepared to comprehend intermediate and advanced statistics in order to be both consumers and producers of current educational leadership research. When more advanced techniques would better answer the research question, our graduates should be armed with the tools to apply the most current research to their own problems of practice and generate new research to add to the field. In this 
way, graduates continue to be scholar-practitioners engaged in the ongoing conversation of research long after the dissertation defense and ultimately better.

As Hutchinson and Lovell conducted their study almost twenty years later, one should consider that the field of advanced statistics has gained some ground. We are not surprised that there has been an evolution from basic statistics to intermediate and advanced as the complexity of the questions we ask increases. We rarely pose questions involving one variable with two groups appropriate for only t-Test analysis devoid of contextual variables. We now think more about interactions and predictive analysis. This informs educational leadership preparation in the areas of curricula, research conducted by faculty members, and contribution to the field. When we refer to the impact graduates of an EdD program might have, we consider the purpose and role research in the professional doctorate plays in transforming institutions of learning (Perry \& Imig, 2016), the changes that are needed in curricula, and faculty development required to reconsider traditional PhD models (Perry, Zambo, \& Abruzzo, 2020). As the research questions become more complex and as we explore models of adult learning that include graduate students working in groups toward a comprehensive dissertation, it is important to take note of how the kind of research that is published reflects what scholars in practice need and will use for systemic and systematic inquiry.

Andragogically, creating a space for teams of graduate students to work toward developing a database of current educational leadership research prepares them to be leaders of teacher teams rather than disseminators of information. When educators work together toward a common goal and share resources, this replicates the meaningful work that professional learning communities can produce. Working in teams may also support using multiple analysis methods to respond to a complex question of practice. The challenge for EdD educational leadership programs is to consider whether or not emergent scholar-practitioners are prepared to use at least intermediate statistics and apply those techniques to complex problems of practice. Furthermore, qualitative methodology accounts for half of the published research in these journals of educational leadership. Qualitative and quantitative methods often require different research methodology courses for educational leadership preparation programs. Whereas we might find this attributed to qualitative and quantitative (at even the intermediate level) in only $\mathrm{PhD}$ programs attending to such research in EdD programs might be atypical. Our claim is that given the context of research from primary sources in our field it is not a luxury but a necessity.

This may require a financial commitment from the university to support library funds for the journals that publish advanced quantitative methods and a stronger collaboration across departments.

\section{Impact in our Educational Leadership Program}

As a result of this research study, our EdD program in Educational Leadership has shifted toward a PK-20 mindset. Concrete steps toward this include collaboration with methodologists to implement several changes. First, we added a higher-level statistics course and a qualitative methodology course to the program of study. This has encouraged more complex research questions that are contextually relevant and reflect what is currently published in the field. Second, 
we are exploring the logistics of a co-advising dissertation model in which one advisor is a faculty member from the educational leadership program and the other co-advisor is a faculty member from the research methods department. While this can be a territorial issue in higher education, with the right support from the administration and a strong relationship across departments, this could greatly strengthen the level of evidence-based research conducted in our PK-12 schools. We have also increased exposure to primary research in the master's and specialist programs by selecting certain journals to highlight in different courses. Our aim is to gradually increase the scholar-practitioner's ability to read, to understand, and to use evidence-based research from toptier journals to guide practice and engage in scholarly conversations. The exponential increase in the number of publications in peer-reviewed journals by our graduates is an indication that the changes have had a positive impact.

\section{Implications for Further Study}

This study provided an initial understanding of the research methods currently published in four top-tier educational leadership journals. A broader understanding may be reached by replicating the study beyond the four journals or beyond the three-year framework. Additionally, the researchers found it easy to adapt the form for a different field of study, thus those in related fields may find the same form a useful tool.

The process was so valuable that it may be beneficial to use this as a teaching strategy in research courses. The form and repetition encourages a deeper understanding of how peer reviewed journals define quality research and the kinds of research journals seek and publish. While we included graduate students in the process, we did not reach a point where they were able to review an article independently. A small team of graduate students could certainly be trained to do so, though time did not permit us to do this with efficiency.

As the study concluded with 2016 journals, the study could again be replicated in two more years to include three additional years of data. We intend to continue to analyze the methodological approaches in the top-tier journals so that we have a database for our own research and our students' research. This would provide an ongoing snapshot of current methodological approaches in the field and support graduate students' ability to synthesize and organize current research beyond their own topics. Replicating the process in teams would also provide graduate students with the multiple perspectives that we found beneficial and introduce a process for establishing inter-rater consistency.

\section{References}

American Psychological Association. (2020). Publication manual of the American Psychological Association ( $^{\text {th }}$ ed.). Retrieved from https://doi.org/10.1037/0000165-000

Byrd, J. K. (2007). A call for statistical reform. Educational Administration Quarterly, 43(3), 381-391.

Goodwin, L. D., \& Goodwin, W. L. (1985). Statistical techniques in “AERJ” articles, 1979-1983: The preparation of graduate students to read the educational research literature. Educational Researcher, 14(2), 5-11.

Google Scholar (2019). Top publications; Educational administration, 2019. Retrieved from https://scholar.google.com/citations?view_op=top_venues\&hl=en\&vq=bus_educationaladministration

Hallinger, P. (2013). A conceptual framework for systematic reviews of research in educational leadership and management. Journal of Educational Administration, 51(2), 126-149. doi: 10.1108/09578231311304670 
Hochbein, C., \& Smeaton, K. S. (2018). An exploratory analysis of the prevalence of quantitative research methodologies in journal articles. International Journal of Education Policy and Leadership, 13(11), 11.

Hutchinson, S. R., \& Lovell, C. D. (2004). A review of methodological characteristics of research published in key journals in higher education: Implications for graduate research training. Research in Higher Education, 45(4), 383-403.

Jackson, K. M. (2019). A review of research methods trends in educational leadership journals. Education Leadership, 119.

Kranzler, J., Floyd, R. G., Bray, M. A., \& Demaray, M. K. (2020, June). Past, present, and future of research in school psychology: The biopsychosocial ecological model as an overarching framework. School Psychology Quarterly.

Little, T. D., Gorrall, B. K., Panko, P., \& Curtis, J. D. (2017). Modern practices to improve human development research. Research in Human Development, 14(4), 338-349. Retrieved from https://doi.org/10.1080/15427609.2017.1370967.

Mayo, C. R., Zirkel, P. A., \& Finger, B. A. (2006). Which journals are educational leadership professors choosing? Educational Administration Quarterly, 42(5), 806-811. doi: 10.1177/0013161X05282603

Perry, J. A., \& Imig, D. G. (2016). What do we mean by impact? Impacting Education: Journal on Transforming Professional Practice, 1(1). doi: 10.5195/ie.2016.26

Perry, J. A., Zambo, D., \& Abruzzo, E. (2020). Faculty Leaders Challenges and Strategies in Redesigning EdD programs. Impacting Education: Journal on Transforming Professional Practice, 5, 1-6. doi: 10.51951/ie.2020.143

Pounder, D. G., \& Johnson Jr., B. L. (2007). Reflections on EAQ's past, present, and future. Educational Administration Quarterly, 43(2), 259-272. doi: 10.1177/0013161X06298593

Richardson, J. W., \& McLeod, S. (2009). Where should educational leadership authors publish to get noticed by the top journals in the discipline? Educational Administration Quarterly, 45(4), 631-639.

Scimago (n.d.). Scimago journal and country rank. Scopus. Scimago Institutions Rankings. Retrieved from https://www.scimagojr.com/journalrank.php?area=3300\&order=h\&ord=desc\&category=3304

Silverman, R. J. (1987). How we know what we know: A study of higher education journal articles. The Review of Higher Education, 11(1), 39-59.

Wells, R. S., Kolek, E. A., Williams, E. A., \& Saunders, D. B. (2015). "How we know what we know": A systematic comparison of research methods employed in higher education journals. The Journal of Higher Education, 86(2), 171-195. 
Appendix A

Journal Coding Form

\section{Coder:}

\section{Do you request a member check?}

Yes

No

Partial check (list specific area)

\section{Journal:}

Educational Administration Quarterly

Journal of School Leadership

Journal of Educational Administration

National Association of Secondary School Principals

\section{Title of Journal Article:}

\section{Keywords:}

\section{Designs used:}

True experiment

Quasi-experiment (regression discontinuity, propensity score, instrumental variables)

Correlational (all correlation, regression, SEM, HLM)

Ex Post facto or causal comparative (all ANOVA, ANCOVA)

Descriptive qualitative

Descriptive quantitative

Developmental/longitudinal

Ethnography

Case study

Historical

Action research

Meta analysis 
Test/scale validation

Other (e.g. content analysis phenomenology, participatory action research)

\section{Broad design type:}

Quantitative only

Qualitative only

Mixed methods

\section{Quantitative}

\section{Data collection:}

survey (primary)

survey (secondary - please identify below in other)

observation

interview/focus groups

documents/artifacts

meta-analysis

test or attitude outcome measure (experiment)

IPEDS (Integrated Postsecondary Education Data Systems from National Center of Education Statistics)

institution person-record data files

Other

\section{Quantitative--types of statistical analysis used- BASIC:}

ANOVA

Bivariate correlations

chi-squared

descriptives (mean, sd, \%)

$\mathrm{T}$ test (ind samples)

$\mathrm{T}$ test (paired)

\section{Quantitative--types of statistical analysis used- INTERMEDIATE:}

ANCOVA (one way)

ANCOVA (factorial)

ANOVA (factorial)

multiple regression

path modeling 
planned orthogonal comparisons

post hoc comparisons

\section{Quantitative--types of statistical analysis used- ADVANCED}

cluster analysis

discriminant analysis

factor or principle component analysis

used to create independent variables

used to create dependent variables

used to directly answer a research question

logistic regression (Probit)

logit/linear

\section{MANOVA/MANCOVA}

repeated measures

structural equation modeling

hierarchical linear modeling (HLM)

other

\section{Descriptives (For descriptive only articles):}

means, sd

$\%$ proportions, frequencies

graphs, charts, figures

\section{Highest level statistics used to answer primary research question:}

basic

intermediate

advanced

\section{Quantitative missing data:}

NA (no missing data, which is a $100 \%$ response rate)

No (they didn't mention any missing data)

Yes, no justification for why specific technique/method chosen

Yes, with any justification for why specific technique/method chosen

\section{Quantitative missing data method:}

mean replacement

list-wise deletion (excluded cases with missing data from analysis) 
pair-wise deletion

multiple imputation/maximum likelihood estimation

other

non-specified

16. Quality of article--provides discussion of statistical assumptions: INTERMEDIATE AND ADVANCED ONLY:

no

yes, minimal (one or two assumptions)

yes, thorough (more than two assumptions)

17. Quality of article--provides clear operational definition of variables (replicability):

no

yes, partial

yes

18. Quality of article--presents scale reliability (latent constructs only):

no scale used (such as inventory or instrument)

no (reliability not discussed)

yes, partial or past

yes (alpha coefficient computed and reported for all latent multi-item measures)

19. Quality of article--presents validity info ONLY FOR SURVEY MEASURES:

no

yes, minimal

yes, thorough (more than one type)

20. Quality of article--for surveys, addresses potential nonrespondent bias:

no

yes

21. Quality of article--researcher bias addressed (includes evaluator effects and power differential effects):

no

yes

22. Open Thoughts from Coder 
Curtin, DeJong, Robinson, Card, and Campoli: Preparing scholar-practitioners for systemic and systematic inquiry: Methodology published and practiced

\section{Qualitative}

23. Quality of article--researcher bias addressed (includes evaluator effects and power differential effects):

no

yes

24. Quality of article--coding process described:

no

yes

25. Quality of article--if interview/focus group recorded:

yes (if recorded for at least half of interviews/focus group)

not specified

no

26. Quality of article--if interview/focus group transcribed:

yes (for at least half of interview/focus groups)

not specified

no

27. Quality of article--triangulation explicitly mentioned:

yes

no

28. Open Comments from Coder: 